\title{
Desulfurization of Vacuum Gasoil by MCM-41 Supported Molybdenum-Nickel Catalysts
}

\author{
Tzong-Rong Ling, ${ }^{* \dagger}{ }^{\dagger}$ Ben-Zu Wan, ${ }^{\ddagger}$ Hong-Ping Lin, ${ }^{\S}$ and Chung-Yuan Mou" \\ Department of Chemical Engineering, I-Shou University, Kaohsiung County, Taiwan, R.O.C., Departments of \\ Chemical Engineering and Chemistry, National Taiwan University, Taipei, Taiwan, R.O.C., and Department of \\ Chemistry, National Cheng Kung University, Tainan, Taiwan, R.O.C.
}

\begin{abstract}
Hydrodesulfurization (HDS) of vacuum gas oil (VGO) was carried out in a trickle bed reactor at $400{ }^{\circ} \mathrm{C}$ and 7.2 MPa with a weight hourly space velocity (WHSV) $=2 \mathrm{~h}^{-1}$ over a series of molybdenum-nickel catalysts, which were prepared by loading the same amounts of $\mathrm{MoO}_{3}(12 \mathrm{wt} \%)$ and $\mathrm{NiO}(3 \mathrm{wt} \%)$ on supports including: tubular shaped MCM-41, nontubular shaped MCM-41, alumina, and silica. The HDS activity of the MoNi catalysts with different supports was investigated. The tubular shaped MCM-41, which possesses a regularly ordered molecular sieve structure, was shown to give significant improvements in the diffusion of large molecules. The results indicated that the tubular shaped MCM-41 supported catalyst has a higher activity than the other catalysts when measured over a $4-5$ day running period. The effect of $\mathrm{Si} / \mathrm{Al}$ ratios in the framework is also discussed. Various methods and techniques were used to characterize the catalysts such as: scanning electron microscopy (SEM), transmission electronic microscopy (TEM), temperature programming reduction (TPR), X-ray diffraction (XRD), mercury-porosity, and the generation of nitrogen adsorption-desorption isotherms.
\end{abstract}

\section{Introduction}

With heightening environmental concerns, cleaner fuel is increasingly in demand. Heavy oils, mostly used as burning oils that contain high percentages of sulfur will be strictly regulated. Catalytic hydrotreatment using supported $\mathrm{Ni}-\mathrm{Mo}$ or $\mathrm{Co}-\mathrm{Mo}$ catalysts is a common process used to remove heteroatoms and upgrade the quality of petroleum in the refining industry. ${ }^{1-3}$ Such desulfurization of heavy oil has been commercialized for many decades. ${ }^{4-6}$ Until now the efficiency and deactivation of catalyst has been a problem attracting extensive research efforts. ${ }^{7,8}$ Two important factors that affect the efficiency and stability of a hydrodesulphurization catalyst are the pore structure of the support ${ }^{4,9,10}$ and interaction between the active phases and the support. ${ }^{9}$ Together, they influence (i) the dispersion of the active components, (ii) their reducibility and sulfidability, and (iii) the accessibility of substrate molecule to the catalytic sites. Thus, finding good support for the Ni-Mo catalyst is still an important problem made more urgent by the stringent regulations concerning the restricted level of sulfur permitted in fuels.

Many kinds of supports have been used in hydrotreating catalyst such as carbon, alumina, mixed oxides, and porous materials. ${ }^{11}$ It has been long known that molybdenum based catalysts interact strongly with supports such as alumina. The interactions between the active-phase and the support, potentially affects the spreading of the catalyst and its reducibility and sulfidability: this has led many researches to examine other supports. With the advent of mesoporous silica materials of large surface area and controllable pore sizes, it is natural for catalysis researchers to examine this material as a support for the hydrodesulfurization catalysts. For example, it has been shown MCM-41 supported $\mathrm{Co}-\mathrm{Mo}^{12}$ or $\mathrm{Ni}-\mathrm{Mo}^{13}$ catalysts are better

* To whom all correspondence should be addressed. E-mail: trling@ isu.edu.tw.

I-Shou University.

¥ Department of Chemical Engineering, National Taiwan University.

$\S$ Department of Chemistry, National Taiwan University.

"National Cheng Kung University. catalysts in comparison to the commercial alumina-supported $\mathrm{Co}-\mathrm{Mo}, \mathrm{Ni}-\mathrm{Mo}$ catalysts used for desulfurization.

The catalytic treatment of heavy oil unavoidably involves the mass transport of large molecules into the catalyst's pores. The large molecules of heavy oil have high boiling points and sticking coefficients, which often cause the deactivation including an irreversible adsorption, cokes deposition, or pore plugging. The mesoporous structure of MCM-41 apparently helps the diffusion of the large S-containing molecules. However, due to the complex distribution of molecule species in real gasoil, the uniform pore size and long channels in the MCM-41 pose a problem for easy transport. To further overcome the problem of diffusion for large molecules, a catalyst with a bimodal pore structure of a macro-mesoporous nature has been proposed as having a good endurance against deactivation even before the advent of mesoporous materials. ${ }^{14-17}$ The bimodal pore structure possesses two pore sizes, i.e. macropore and mesopore. The primary function of the macropore is to provide diffusion paths for transporting large molecules to the reaction sites. The effective diffusivity of the bimodal pore structure catalyst was much higher than that of unimodal pore structure catalyst with the same mesopore diameters. ${ }^{14}$

Since the mesoporous materials were synthesized, ${ }^{18}$ the adjustable and uniform sizes in a range of 1.5-10 nm have attracted the attention of scientists. ${ }^{19}$ The high surface area (1000 $\mathrm{m}^{2} / \mathrm{g}$ ) and the large pore structure may lead to applications in many areas; especially in catalysis, sorption, and coating. In particular, since the early days of its discovery MCM- 41 has been examined as a support for catalysis in the hydrotreatment of oil. ${ }^{20-22}$ It was found that the introduction of heteroatoms such as $\mathrm{Al}$ and Ti into the framework of MCM-41 improves hydrothermal stability in hydrodesulfurization (HDS) ${ }^{23}$ For the more refractory sulfur compounds such as dibenzothiophenes (DBT), studies have shown that mesoporous MCM-41 supported catalysts have better activity than the microporous $\mathrm{SiO}_{2}-\mathrm{Al}_{2} \mathrm{O}_{3}$ and Y-zeolite supported catalyst in desulfurization of vacuum gas oil (VGO) ${ }^{24-27}$ In general, sulfur components in VGO are complex molecules. The most refractory sulfur-containing 
polyaromatic compounds are thiophene, benzothiophene, and their derivatives. They often possess a high molecular weight with a low mass transfer coefficient. Therefore, HDS is often operated at a high temperatures to increase the mass transfer of the target molecules (sulfur component) to react with the active site on the catalytic surface. Meanwhile, the complex reactions of VGO desulfurization occur simultaneously, e.g. $\mathrm{C}-\mathrm{S}$ bond hydrolysis of the HDS reaction, and $\mathrm{C}-\mathrm{C}$ bond hydrolysis of the hydrocracking reaction. However, the pore size of $\sim 3 \mathrm{~nm}$ in MCM-41 is seemingly not big enough to accommodate and transport large-sized molecules such as asphaltenes in the petroleum residues. ${ }^{2}$ Recently, $\mathrm{Xu}$ and co-worker ${ }^{28}$ found that a macroporous $\mathrm{NiMo} / \mathrm{Al}_{2} \mathrm{O}_{3}$ catalyst prepared by coprecipitation shows a superior durability because of its macroporous structure. Combined with the large surface area of MCM-41, it would be highly desirable to use as a support with a particular form of MCM-41 to give interior macropores interdispersed among the mesopore. This kind of hierarchical structure with simultaneous macropore and interconnected mesopores has been intensively studied recently. ${ }^{29}$ Previously, MCM-41 of tubular morphology has been successfully synthesized through a specific acidification process. ${ }^{30-32}$ This material, of hollow tubule form with a diameter of about $0.1-0.3 \mu \mathrm{m}$, possesses many macroporous voids distributed among the mesopore diameter, ${ }^{33-35}$ such that the linear mesopores become interconnected through the macropores among them. The hierarchical order of the molecular sieve structure is expected to give a significant improvement in the diffusion of large molecules, especially the heavy oil for the hydrogen desulfurization process. Previously, we have shown the tubular form of MCM-41 is an effective catalyst in the hydrocracking of tri-isopropylbenzene ${ }^{36}$ or an excellent support for $\mathrm{MoO}_{3}$ for the dehydrogenation of ethylbenzene. ${ }^{37}$ The improved diffusion of reactant/products in both cases was helped by the macropore/mesoppore combination and the center tubular space in its structure.

In this work, we used two forms of MCM-41, i.e. the regular and the tubular forms as supports for the $\mathrm{Ni}-\mathrm{Mo}$ catalyst to study the catalytic activities in the desulfurization of vacuum gas oil (VGO). The support's effects on the mass transfer of the VGO molecules were investigated by loading the same amount of $\mathrm{NiO}$ and $\mathrm{MoO}_{3}$ onto different supports. It is hoped to provide an useful information for morphology development of MCM-41 and the possible application of big pores of tubular shape MCM-41 in hydrodesulfurization of vacuum gas oil (a heavy oil).

\section{Experimental Details}

2.1. Catalyst Preparation. A high yield of the tubular shaped MCM-41 was synthesized by precisely controlling the acidification rate of silicate using a delayed-neutralization method as detailed in our previous reports. ${ }^{30,31}$ The conventional nontubular shape MCM-41 was made by instantaneously adding the sulfuric acid solution to carry out the acidification of silicate rapidly. Catalysts were prepare by a wet-incipient method with the appropriate amount of an aqueous solution of ammonium heptamolybdate (AHM) and nickel nitrate $(\mathrm{NN})$ for obtaining 12 wt $\% \mathrm{MoO}_{3}$ and 3 wt $\% \mathrm{NiO}$ loaded onto the supports including tubular shaped MCM-41, nontubular shaped MCM41, alumina, and silica. The metal solutions were prepared based in the ratio: $0.35 \mathrm{~mL}$ per gram support $(\mathrm{mL} / \mathrm{g})$. First, the wetincipient method was carried out by dropping the AHM solution into the support powder of 30-70 mesh in well-mixed conditions. Then, the impregnated support powder was dried at 110 ${ }^{\circ} \mathrm{C}$ overnight. Second, the NN solution was loaded following
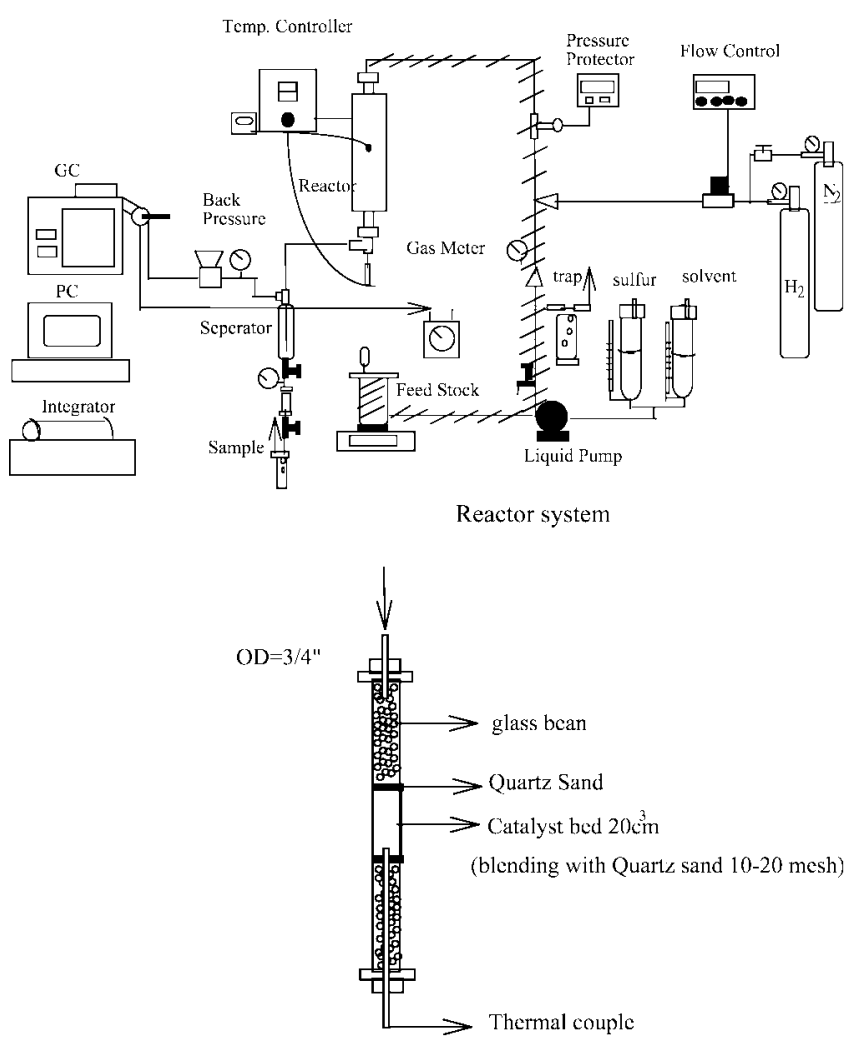

Side view of reactor tube

Figure 1. Schematic diagram of the HDS of VGO system (bench scale).

the same process: dropping, mixing, and drying. Finally, the support powder was calcinated by increasing the temperature at a rate of $2{ }^{\circ} \mathrm{C} / \mathrm{min}$ to $550{ }^{\circ} \mathrm{C}$ and maintained at this temperature for $6 \mathrm{~h}$. Theoretically, the ammonium heptamolybdate and nickel nitrate can be completely oxidized into their oxide forms $\mathrm{MoO}_{3}$ and $\mathrm{NiO}$ in such thermal treatment condition.

2.2. Characterization. The morphology of the catalysts was observed by scanning electron microscopy (SEM), Hitachi S-2400 model, and the crystal structure was analyzed by X-ray powder diffraction (XRD), MO3XHF. The specific areas and mesopore size distributions of the catalysts were measured by the adsorption-desorption isotherms of nitrogen at $77 \mathrm{~K}$ with ASAP-2000 apparatus and calculated using the Barett-JoynerHalenda (BJH) method. A mercury porosity meter (Autopore II 9220) was used to estimate the pore size larger than $3 \mathrm{~nm}$. The dispersion of metal oxide onto the different supports was examined by hydrogen temperature programmed reduction $\left(\mathrm{H}_{2^{-}}\right.$ TPR) method.

2.3. Desulfurize VGO Reaction. The desurfurization of VGO was performed in a fixed bed reactor system made of a stainless steel 316 tube as shown in Figure 1. Catalyst particles of 30-70 mesh were diluted with quartz $10-20$ mesh and packed into the reactor. The feedstock, untreated VGO containing sulfur (2.06 wt \%), was provided by the Chinese Petroleum Corporation, and its properties are shown in Table 1. Before the reaction, a presulfide process was carried out by using 2 wt \% sulfur mixture of dimethyl disulfide (DMDS) and paraffin oil, which was passed through the reactor at $400{ }^{\circ} \mathrm{C}$ and 7.2 MPa for $12 \mathrm{~h}$. The weight hourly space velocity (WHSV) of the liquid feedstock was kept at $2 \mathrm{~h}^{-1}$, which is the rate of feeding mixture weight $(\mathrm{g} / \mathrm{h}) /$ catalyst weight $(\mathrm{g})$. And, the $\mathrm{H}_{2}$ gas flow rate was $600 \mathrm{~N} \mathrm{~mL} / \mathrm{g}$ based on the rate of feed $\mathrm{H}_{2} /$ rate of feeding mixture. In a typical run, the desulfurization activity of the catalyst was examined at WHSV $=2 \mathrm{~h}^{-1}$ based on the 
Table 1. Properties of Untreated Vacuum Gas Oil Feedstock

\begin{tabular}{lll}
\hline \multicolumn{1}{c}{ item } & & value \\
\hline sulfur & wt \% & 2.06 \\
nitrogen & ppm & 1060 \\
vanadium & ppm & 0.83 \\
nickel & ppm & 1.56 \\
API & D-1298 & 23.4 \\
CCR & D-4530 & 0.62 \\
\hline \multicolumn{2}{c}{ distillation range D-1160 } & deg C \\
\hline & IBP & 254.4 \\
& $10 \%$ & 348.6 \\
& $30 \%$ & 427.1 \\
& $50 \%$ & 471.1 \\
& $70 \%$ & 512.1 \\
& $90 \%$ & 566.7 \\
& FBP & 574.5
\end{tabular}

flow rate of feeding untreated VGO weight $(\mathrm{g} / \mathrm{h}) /$ catalyst weight (g) and $\mathrm{H}_{2} /$ feeding untreated $\mathrm{VGO}=600 \mathrm{~N} \mathrm{~mL} / \mathrm{g}$ (the hydrogen in excess of sulfur content in the feeding untreated VGO) at a reaction temperature of $400{ }^{\circ} \mathrm{C}$ and pressure of $7.2 \mathrm{MPa}$.

2.4. Sample Analysis. The liquid product was sampled for analysis at intervals of $3-7 \mathrm{~h}$ for a period of $4-5$ days while running the test. The amount of sulfur in the liquid products was measured by X-ray fluorescence (XRF), Oxford Laboratory$\mathrm{x} 1000$. The activity of desulfurization was evaluated based on the percentage of sulfur removal in the feedstock, it was calculated as

$$
\text { sulfur removal }(\%)=\left([\mathrm{S}]_{\text {in }}-[\mathrm{S}]_{\text {out }}\right) /[\mathrm{S}]_{\text {in }} \times 100 \%
$$

where $[\mathrm{S}]_{\text {in }}$ and $[\mathrm{S}]_{\text {out }}$ are the experimentally measured inlet and outlet sulfur contents. The gas product was analyzed online by gas chromatography (GC) with a Porapak Q column. Gases such as $\mathrm{H}_{2} \mathrm{~S}, \mathrm{CH}_{4}, \mathrm{C}_{2} \mathrm{H}_{6}, \mathrm{NH}_{3}, \mathrm{C}_{3} \mathrm{H}_{8}$, and $\mathrm{H}_{2} \mathrm{O}$ were mainly from the desulfuriztion and cracking of VGO. The analysis of gas products also provides information as to the activity of desulfurization and the extent of cracking. There is not much difference among MoNi catalysts with various supports. It is probably that excess reactant, i.e. $\mathrm{H}_{2}$ was used in the system. Thus, the quantitative analysis of gas product is roughly recorded by gas flow meter. The higher gas flow rate was found at the higher reaction temperature. It is possibly to increase both hydrodesulfurization and hydrocracking at high temperatures.

\section{Results and Discussion}

3.1. Morphology and Mesostructure of the Different Supports. Figure 2a shows the scanning electron microscopy (SEM) photograph of the tubular shaped MCM-41. Figure 2b shows the regular nontubular shaped MCM-41. Although these two materials are markedly different in their shapes from the SEM observation, both have the same crystal structure of MCM41 identified by their XRD patterns. As one can see from the transmission electronic microscopy (TEM) micrographs as shown in Figures $3 a$ and $b$, the two samples have the same mesochannel structure but quite different defect structures. ${ }^{38}$ Tubular MCM-41 has an extensive set of larger pores (void of size $\sim 30 \mathrm{~nm}$ ) dispersed among the nanochannels of MCM-41, while the regular MCM-41 has perfect linearly arranged nanochannels. One can see immediately that the nanochannels in tubular MCM-41 would be interconnected and give better material transport.

Figure 4 shows the XRD spectra of the mesoporous supports with or without loadings of the NiMo catalysts. As one can see, both MCM-41 samples, tubular or nontubular, give excellent 2D hexagonal mesostructure and show five XRD peaks. After (a)

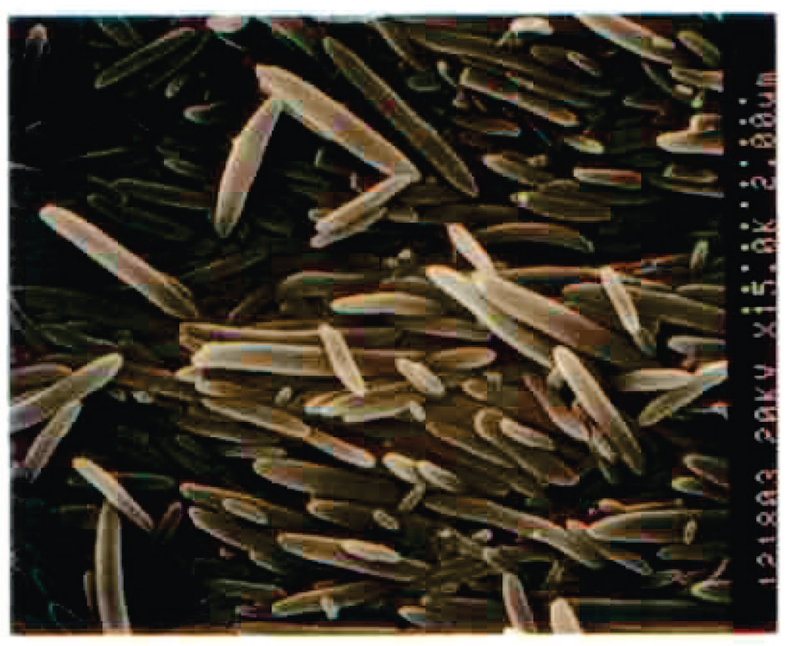

(b)

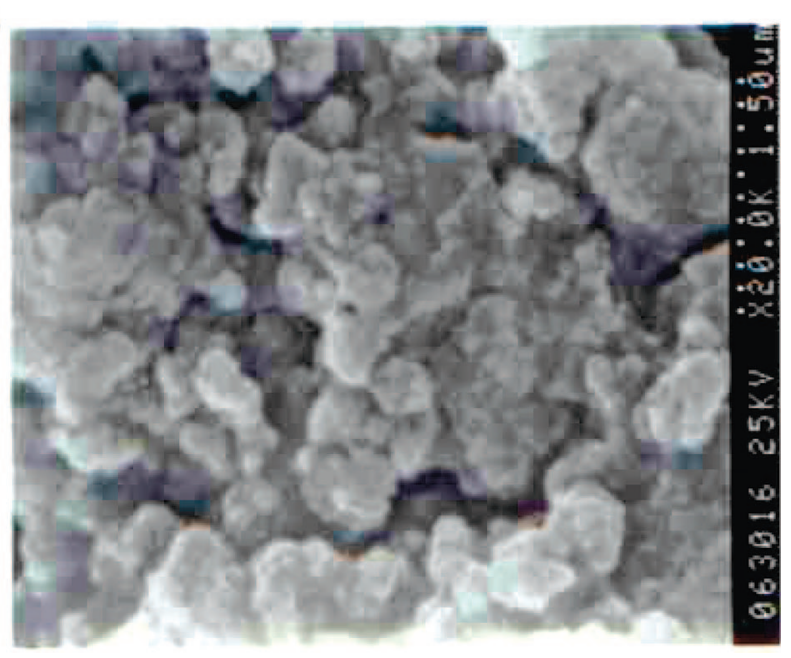

Figure 2. Scanning electronic microscopy (SEM) photograph of (a) tubular shaped MCM-41 and (b) nontubular MCM-41.

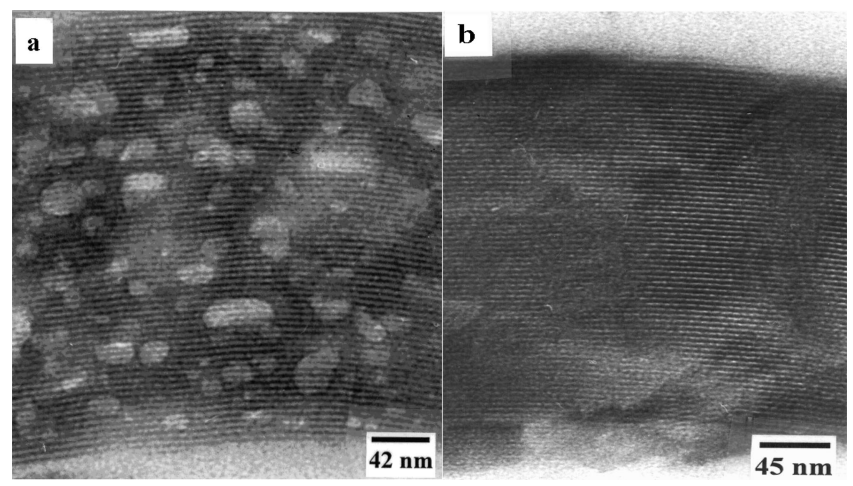

Figure 3. Transmission electronic microscopy (TEM) photograph of (a) tubular shaped MCM-41 and (b) nontubular MCM-41.

NiMo catalysts were loaded by the wet-incipient method, the tubular MCM-41 sample (a(2)) showed a much lower XRD intensity for all peaks than did nontubular MCM-41(b(2)). Because of the proportional lowering of intensity for all peaks, it is not due to structural collapse of the mesopores. It is due to the decreased X-ray diffraction contrast upon loading NiMo species. Thus, we can conclude that with the same loading amounts of $\mathrm{NiO}(3 \mathrm{wt} \%)$ and $\mathrm{MoO}_{3}(12 \mathrm{wt} \%)$, the tubular MCM-41 support gives higher and more uniform loadings inside the pore wall. This may be due to the more effective interconnections among the nanochannels which may have led to better 

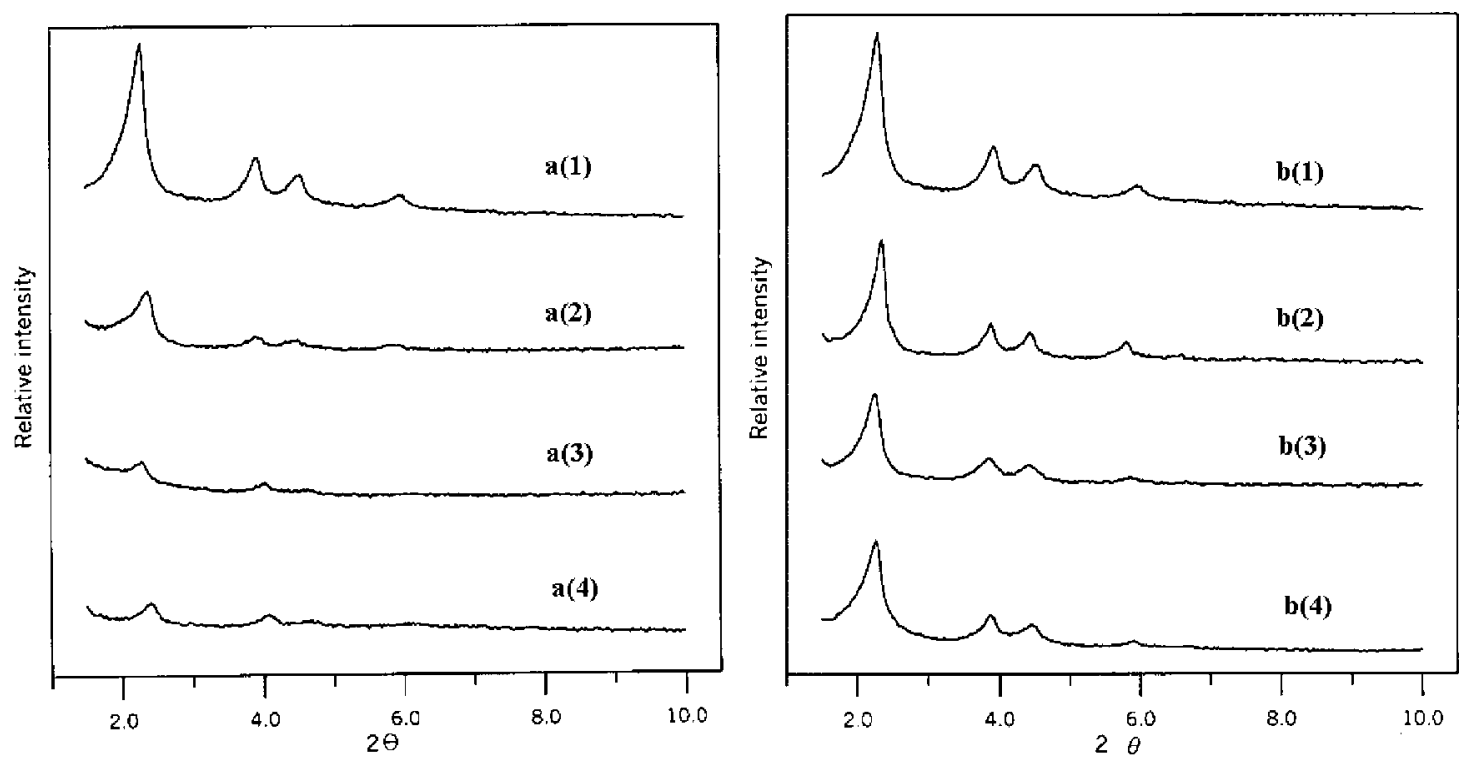

Figure 4. XRD patterns of tubular MCM-41(a) and nontubular MCM-41(b) based catalysts under different treatment process. (1) Tubular shaped MCM41(a) and nontubular MCM-41(b). (2) $\mathrm{NiO}\left(3 \mathrm{wt} \%\right.$ ) and $\mathrm{MoO}_{3}(12 \mathrm{wt} \%$ ) were loaded onto the sample in 1 by the wet-incipient method. (3) After $\mathrm{HDS}$ running test of the sample in 2 and drying. (4) The coke from the sample in 3 has been burned out.

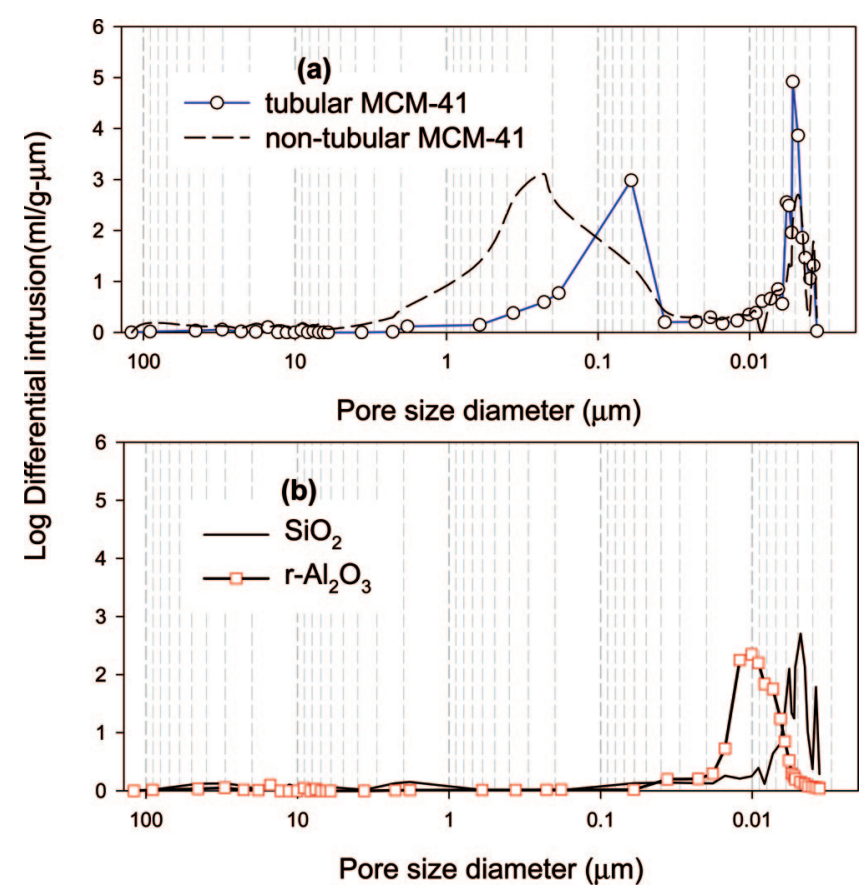

Figure 5. Pore size distribution of supports with (a) bimodal pore structure and (b) unimodal structures measured by mercury porosity meter. (a) Tubular shape MCM-41 and nontubular MCM-41. (b) $\mathrm{r}-\mathrm{Al}_{2} \mathrm{O}_{3}$ and $\mathrm{SiO}_{2}$.

spreading of the NiMo mixed oxide on the support. On the other hand, the regular MCM-41 with its very long and uninterupted channels would be less favorable for the spreading of NiMo catalyst.

3.2. Pore Structure of MCM-41. For the support materials used in this work, there are three hierarchical levels of pores in the range of $2.3,5$, and $50 \mathrm{~nm}$. Therefore, we employ two methods of pore size determination, i.e., mercury porosity meter and nitrogen adsorption. Figure 5 shows the pore structure of different supports measured by the mercury porosity meter. The tubular MCM-41 exhibits a bimodal pore structure having macropores 40-200 $\mathrm{nm}$ and mesopore $4-6 \mathrm{~nm}$. It is different from the nontubular shape MCM-41, in the range of macropore size. Obviously, the macropores of the tubular shape MCM-41 are related to its void and hollow structure. The nontubular shape MCM-41 has broader profile of macropore, due to its irregular shape of particulate, as shown in Figure 5a. Both tubular and nontubular structures show similar profiles to mesopores with diameters of 4-6 nm. To compare with other supports, Figure $5 \mathrm{~b}$ also shows the typical supports: $\gamma-\mathrm{Al}_{2} \mathrm{O}_{3}(8-15 \mathrm{~nm})$ and $\mathrm{SiO}_{2}(3-7 \mathrm{~nm})$ giving unimodal mesopore profiles. The profile of macropore in MCM-41 measured by mercury porosity meter was not changed obviously after loaded with 12 wt $\% \mathrm{MoO}_{3}$ and 3 wt $\% \mathrm{NiO}$.

The mesopore size distribution of the MCM-41 can be observed by the $\mathrm{N}_{2}$ desorption isotherm method in detail as shown in Figure 6. Originally, MCM-41 having numerous mesopores appears at diameters of $2.3-2.5 \mathrm{~nm}$, and some pores appear at diameters of 3.3-4.0 nm in Figure 6a. The pore size patterns were similar between tubular shape MCM41 and conventional nontubular shaped MCM-41 in Figure 6c. Both of them were changed by loading $12 \mathrm{wt} \% \mathrm{MoO}_{3}$ and 3 wt $\% \mathrm{NiO}$. Especially, the tubular MCM-41, in Figure $6 \mathrm{~b}$, was significantly decreased at a pore size diameter of 2.0-2.6 nm, probably due to pore plugging after the wetincipient impregnation process. However, the nontubular shape MCM-41, in Figure 5c, was only slightly influenced by the loaded $\mathrm{Mo}-\mathrm{Ni}$, in Figure $6 \mathrm{~d}$.

Therefore, combining the three characterization techniques of TEM, the mercury porosity meter, and nitrogen adsorption, we have found that the tubular MCM-41 materials are rather unique in their pore structures. The pores consist of a range of pore sizes of 2.3, 5, and $50 \mathrm{~nm}$ (and above) arranged such that they are hierarchical in relation to each other. The smallest pore sizes are the hexagonally arranged nanochannels. The $5 \mathrm{~nm}$ pores are the intraparticle voids distributed among the channels. The $50 \mathrm{~nm}$ pores (and above) are the interparticle textural spaces. The tubular particles surround these macropores. One can expect facile transport of large molecules in the liquid state through the hierarchically distributed pore structure.

3.3. Temperature Programmed Reduction (TPR) Analysis. Temperature-programmed reduction is a powerful tool for studying the reduction behavior of supported phases; the reduction profiles of oxide precursors provide information about the degree of interaction between the supported phase and the 


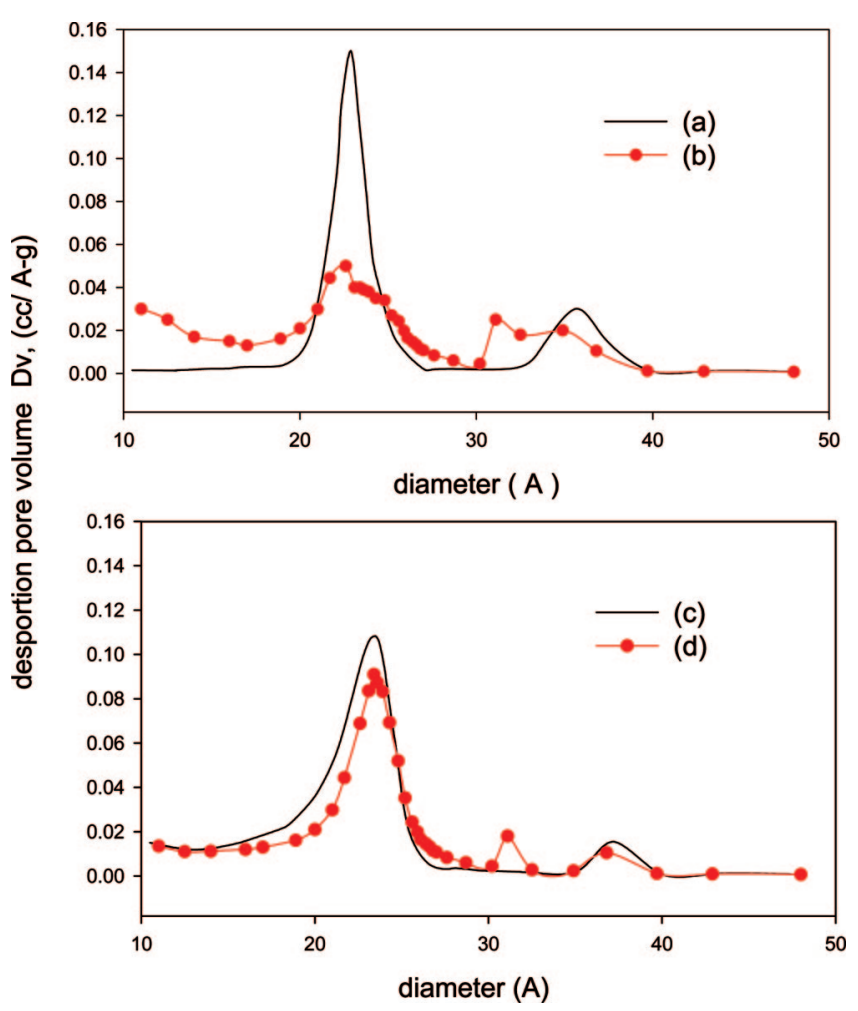

Figure 6. Mesopore size distribution of MCM-41 based catalysts measured by $\mathrm{N}_{2}$ desorption isotherm method. (a) Tubular shaped MCM-41. (b) 12 wt $\% \mathrm{MoO}_{3}, 3$ wt $\% \mathrm{NiO} /$ tubular MCM-41. (c) Nontubular MCM-41. (d) 12 wt $\% \mathrm{MoO}_{3}, 3$ wt $\%$ NiO/nontubular shaped MCM-41.

support. The metal oxides, $\mathrm{MoO}_{3}$ and $\mathrm{NiO}$, which were spread on the support for extending their contact area, play the role of active sites to catalyze the reaction. In TPR analysis, they were reduced into the lower oxidation state by uptaking hydrogen gas in a rising temperature process. For the supported NiMo oxides studied, a lower temperature of hydrogen uptake usually means better spreading on the silica producing smaller nanoparticle or even a monolayer which is easier to reduce. TPR measurements were performed with the catalysts in the oxide form.

Figure 7 give the TPR results for our catalysts in comparison with the standard alumina and $\mathrm{SiO}_{2}$ supports. It is striking that the mesoporous supports gave TPR peaks at much lower temperatures (around $400{ }^{\circ} \mathrm{C}$ ) than that of silica gel (around $512^{\circ} \mathrm{C}$ ). In fact, most NiMo catalysts reported in the literature gave the first TPR peak between 450 and $500{ }^{\circ} \mathrm{C} .{ }^{39}$ Given the similarity in surface structures (amorphous silica), the mesoporosity in MCM-41 probably helps the spreading of NiMo oxides to give more reducible mixed metal oxides. As shown in Figure 7, the hydrogen consumption peak of tubular shaped MCM-41 (pure silica) catalyst located at $373{ }^{\circ} \mathrm{C}$ is lower than that of the tubular shaped MCM-41 ( $\mathrm{Si} / \mathrm{Al}=33)$ catalyst at $399^{\circ} \mathrm{C}$. The framework of tubular shape MCM-41 containing Al decreased the reduction activity probably related to Lewis acid sites. The acidity might cause the disadvantageous to the reduction of $\mathrm{NiO}$ and $\mathrm{MoO}_{3}$ on the MCM-41. The first reduction peak of the $\mathrm{MoO}_{3}$ and $\mathrm{NiO}$ loaded on nontubular shape MCM41 (pure silica) appeared at $417{ }^{\circ} \mathrm{C}$ which was significantly higher than the tubular shape MCM-41 (pure silica). Obviously, the TPR activity of tubular shaped MCM-41 catalyst is higher than that of nontubular shape MCM-41 catalyst. The result also implies that the tubular shape MCM-41 catalyst will have a higher reaction activity than the nontubular shape MCM41catalyst.

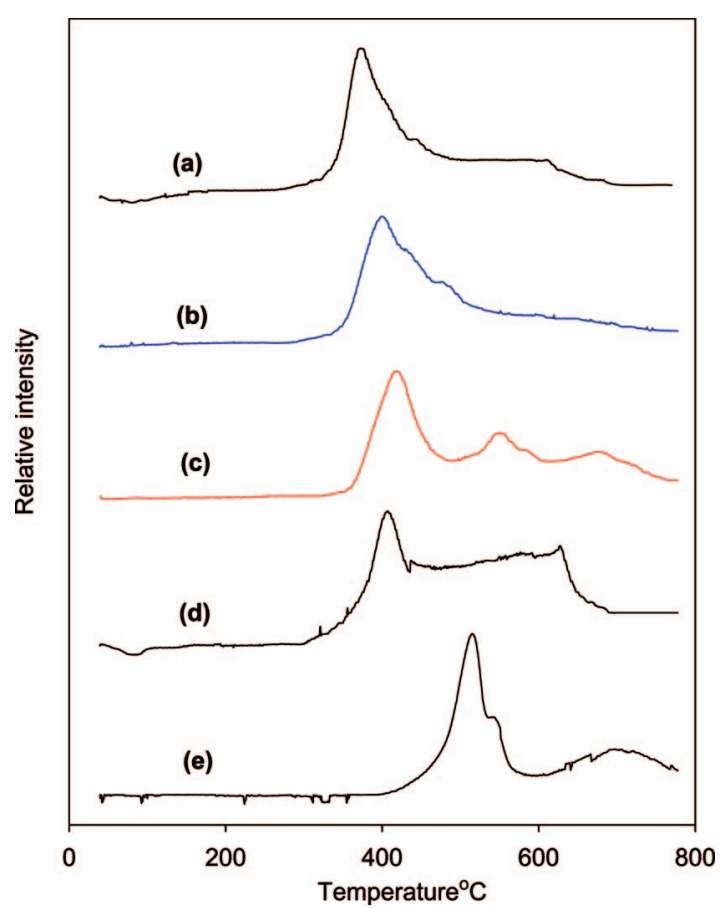

Figure 7. TPR profile of catalysts prepared by loading $\mathrm{MoO}_{3}(12$ wt $\%)$ and $\mathrm{NiO}(3 \mathrm{wt} \%)$ on different supports. (a) Tubular shaped MCM-41 (pure silica). (b) Tubular shaped MCM-41 ( $\mathrm{Si} / \mathrm{Al}=33)$. (c) Nontubular MCM41(pure silica). (d) $\gamma-\mathrm{Al}_{2} \mathrm{O}_{3}$. (e) $\mathrm{SiO}_{2}$.

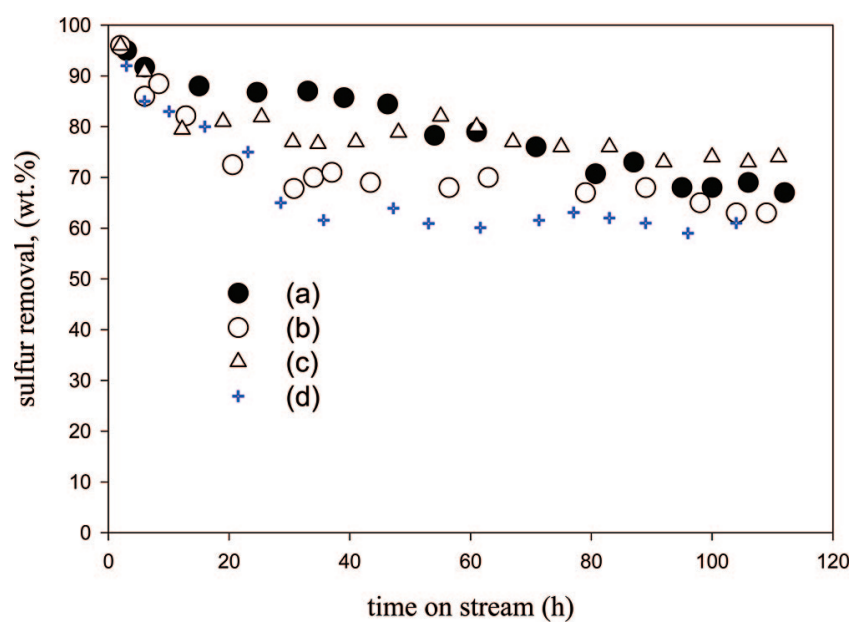

Figure 8. Desulfurization activity of VGO for Mo-Ni catalysts with different supports. The reaction conditions are as follows: $673 \mathrm{~K} ; 7.2 \mathrm{MPa}$; $\mathrm{WHSV}=2 \mathrm{~h}^{-1} ; \mathrm{H}_{2} /$ feed $=600 \mathrm{~N} \mathrm{~mL} / \mathrm{g}$. (a) Tubular shaped MCM-41 (pure silica). (b) Nontubular MCM-41 (pure silica). (c) $\mathrm{r}-\mathrm{Al}_{2} \mathrm{O}_{3}$. (d) $\mathrm{SiO}_{2}$.

To compare with other reference supports such as $\mathrm{SiO}_{2}$ and $\mathrm{Al}_{2} \mathrm{O}_{3}$, Figure 7 shows the TPR profile of the different supports loaded the same amount of $\mathrm{NiO}$ and $\mathrm{MoO}_{3}$. The hydrogen consumption peak of $\mathrm{Al}_{2} \mathrm{O}_{3}$ catalyst is located at $512{ }^{\circ} \mathrm{C}$. This temperature is also higher than the tubular MCM- 41 catalyst. Accordingly, the tubular shape MCM-41 catalyst is more easily reduced than the commonly used alumina support. It is expected that $\mathrm{NiO}$ and $\mathrm{MoO}_{3}$ dispersed on the tubular MCM-41 has a higher activity than that on $\mathrm{Al}_{2} \mathrm{O}_{3}$.

3.4. Activity of Desulfurization. Figure 8 shows the desulfurization activities of VGO for the different MCM-41-based catalysts. The tubular MCM-41 catalyst remarkably exhibits a higher activity than the nontubular MCM-41 catalyst during the first $4-5$ days of running test. The narrow profile of macropore in the tubular MCM-41 catalyst might have a lower resistance 
for diffusion of VGO molecule than the broad profile of macropore in the nontubular MCM-41 catalyst. Al content in the MCM-41 framework also influenced the desulfurization activity. As shown in Figure 8, the tubular MCM-41 catalyst with pure silica (pure silica) has a higher activity than the MCM41 catalyst $(\mathrm{Si} / \mathrm{Al}=33)$. The acidity of the MCM-41 catalyst $(\mathrm{Si} / \mathrm{Al}=33)$ is higher than the MCM-41 catalysts with $\mathrm{SiO}_{2}$, it might cause the coking deposition or some electron effect that are disadvantageous to the desulfurization reaction. However, the deactivation mechanism of the MCM-41catalysts is still unresolved.

The tubular MCM-41 (pure silica) catalyst shows higher activity of desulfurization than the alumina and silica catalysts at the beginning of 4-5 days, as shown in Figure 8. The activities follow the sequence as follows: tubular MCM-41 > $\mathrm{Al}_{2} \mathrm{O}_{3}>\mathrm{SiO}_{2}$. Although the tubular MCM-41 catalyst exhibits the highest initial activity, a faster deactivation than the alumina catalyst was found. Because the tubular shaped MCM-41 has a relatively high surface area and a multimodal hierarchical pore size structure; it shows a better performance in desulfurizing $\mathrm{VGO}$ at the beginning period of $2-3$ days. The interconnection between mesopores and the interparticle macropores make materials transport in this materials particularly easy. Recently, Tan et al. ${ }^{40}$ used bimodal micromesoporous aluminosilicates for heavy oil cracking and found improved activity due to the increased interconnection between mesopores through the interdispersed micropores. However, we believe the micropores may be too small for some of the larger refractory S-containing compounds.

Since our early reports relating to tubular MCM-41, 30,31,35 there have been reported improvements in the pore/void combination structure which may be more stable under high temperature conditions. ${ }^{41,42}$ Thus, further improvements in catalytic performance may be expected using more stable mesoporous silica support.

However, although the mesopore of the MCM-41 catalyst $(2.0-2.6 \mathrm{~nm})$ is smaller than that of $\mathrm{Al}_{2} \mathrm{O}_{3}$ catalyst $(8-12 \mathrm{~nm})$; it may not be large enough to avoid coking and the MCM-41 catalyst decays faster than the $\mathrm{Al}_{2} \mathrm{O}_{3}$ catalyst with unimodal pore structure. The macropores of tubular MCM-41 (40-200 nm) could provide the diffusion path for some large molecule in $\mathrm{VGO}$, but the major reaction takes place on the inside of mesopores. The more active catalyst in NiMo supported on tubular MCM-41 may also lead to faster coking and thus deactivation. In Figure $8, \mathrm{SiO}_{2}$ catalyst with unimodal pore structure shows the lowest activity. The possible reason is that the pore size of the $\mathrm{SiO}_{2}$ catalyst with diameter of $(3-5 \mathrm{~nm})$ is still too small to provide the space for the reaction of VGO molecule and there is no hierarchical pore structure for the easy transport of the reactants and products.

The desulfuriztion activity of $\mathrm{Mo}-\mathrm{Ni}$ catalysts and their properties are summarized in Table 2. $\mathrm{Mo}-\mathrm{Ni} /$ tubular shape MCM-41 is the most active catalyst; the average activity is $0.0321 \mathrm{~g}$-sulfur/g-catalyst $\cdot \mathrm{h}$ at $400{ }^{\circ} \mathrm{C}$. The lowest activity is $0.0267 \mathrm{~g}$-sulfur $/ \mathrm{g}$-catalyst $\cdot \mathrm{h}$ for $\mathrm{Mo}-\mathrm{Ni} / \mathrm{SiO}_{2}$ catalyst. The result of desulfurization activity is analogous with TPR activity. The pore size distribution and surface area of catalyst are two important factors to determine its catalytic performance. The bimodal pore structure of the MCM-41 catalyst provides a high surface area and macropores, resulting in high desulfuriztion activity at the initial stage. To compare with the unimodal pore structure of $\mathrm{Al}_{2} \mathrm{O}_{3}$ and $\mathrm{SiO}_{2}$ catalysts, the function of macropore in the tubular MCM-41 was not obviously to improve the activity in the desulfuriztion of VGO due to the mesopore of
Table 2. Desulfurization Activities of VGO over Ni-Mo Catalyst Based on Different Supports and Their Properties

\begin{tabular}{|c|c|c|c|c|}
\hline \multirow[b]{2}{*}{$\begin{array}{c}\text { support of } \mathrm{Ni}- \\
\text { Mo catalyst }\end{array}$} & \multirow[b]{2}{*}{$\begin{array}{l}\text { ratios of } \\
\mathrm{Si} / \mathrm{Al}\end{array}$} & \multicolumn{2}{|c|}{$\begin{array}{c}\text { surface area BET } \\
\left(\mathrm{m}^{2} / \mathrm{g}\right)\end{array}$} & \multirow{2}{*}{$\begin{array}{c}\text { mean activity } \\
\text { at } 400{ }^{\circ} \mathrm{C}^{a} \\
\text { (g-sulfur/g-catalyst } \cdot \mathrm{h}\end{array}$} \\
\hline & & $\begin{array}{l}\text { before } \\
\text { loading }\end{array}$ & $\begin{array}{c}\text { after } \\
\text { loading }\end{array}$ & \\
\hline tubular MCM-41 & 33 & 934.2 & 408.5 & 0.0298 \\
\hline nontubular MCM-41 & $\infty$ & 875.3 & 762.2 & 0.0235 \\
\hline tubular MCM- $41^{b}$ & $\infty$ & 1020.5 & 363.5 & 0.0329 \\
\hline $\mathrm{r}-\mathrm{Al}_{2} \mathrm{O}_{3}$ & & 162.8 & 138.9 & 0.0294 \\
\hline $\mathrm{SiO}_{2}$ & & 354.3 & 302.1 & 0.0219 \\
\hline
\end{tabular}

${ }^{a}$ Average activity based on sulfur removal rate per gram catalyst during 3 days at the beginning. ${ }^{b}$ NiMo catalyst prepared by the wet-incipient method based on the same amount of loading 3 wt \% NiO and 12 wt $\% \mathrm{MoO}_{3}$ on the supports.

MCM-41 with diameter of $1.8-2.8 \mathrm{~nm}$. This can be proved from the fast deactivation of the tubular MCM-41 catalysts. For desulfurization of VGO, the multimodal pore structure of MCM41 catalysts only exhibits their distinguished performance at the beginning. However, some smaller molecules, for example diesel oil, might be better to convert in this mesopore, and the tubular MCM-41 providing a narrow profile of bimodal pore size and high surface area is worthy of further study in various applications such as demetallization or catalytic fuel process.

Finally, XRD was used to examine the stability of the catalytic materials after a long period of running the test. The low angle XRD pattern of tubular MCM-41 (a) and nontubular MCM-41 (b) catalysts are shown in Figure 4 under different treatment conditions. In step 3, the catalysts is dried after a run of $120 \mathrm{~h}$ of HDS reaction. Both $a(3)$ and $b(3)$ catalysts show further decrease of intensities in the XRD peaks. Due to the coke deposition on the catalysts, the contrast in XRD of the MCM41 catalyst was slightly reduced. However, activity was largely recovered after burning out the coke on the MCM-41catalysts in step 4 .

\section{Conclusions}

Tubular shaped MCM-41 is rather unique in its hierarchical pores structure in consisting of pore sizes of $\sim 2.3,5$, and 50 $\mathrm{nm}$ (and above). For desulfurization of VGO, the tubular MCM41 , which has regular and uniform pore structure, provides a significantly higher activity than the nontubular shaped MCM41 catalyst when loaded with $\mathrm{MoO}_{3}$ (12 wt \%) and $\mathrm{NiO}$ (3 wt \%). $\mathrm{Al}$ in the framework of the tubular shape MCM-41 ( $\mathrm{Si} /$ $\mathrm{Al}=33$ ) catalyst has lower activity than the tubular shape MCM-41 (pure silica). To compare with unimodal pore structure catalysts, $\gamma-\mathrm{Al}_{2} \mathrm{O}_{3}(8-15 \mathrm{~nm})$ and $\mathrm{SiO}_{2}(3-7 \mathrm{~nm})$, the tubular shape MCM-41 also exhibits higher average activity for 4-5 days running period, the average activities in the order: tubular shape MCM-41 (pure silica) $>\gamma-\mathrm{Al}_{2} \mathrm{O}_{3}>\mathrm{SiO}_{2}$. Due to the tubular shape, MCM-41 has relatively high surface area and trimodal pore size structure; it shows a good performance in desulfurization of VGO during running period of 2-3 days. However, a faster deactivation than $\gamma-\mathrm{Al}_{2} \mathrm{O}_{3}$ catalyst was found, as the mesopore of the MCM-41 catalyst is still not large enough to convert the VGO molecule so that the tubular shape MCM41 catalyst decayed faster than the $\gamma-\mathrm{Al}_{2} \mathrm{O}_{3}$ catalyst. The present results might help direct future research in the application of tubular shaped MCM-41 toward some potential applications with respect to the reactions of smaller molecules. 


\section{Acknowledgment}

The financial support of this work by Chinese Petroleum Corporation of the Republic of China was great acknowledgement (grant no.: CPC-S86-032).

\section{Literature Cited}

(1) Sherwood, D. E., Jr. Dai, P.S. E. US patent 5,928,499, 1999.

(2) Reddy, K. M.; Wei, B. L.; Song, C. S. Mesoporous Molecular-Sieve MCM-41 Supported Co-Mo Catalyst for Hydrodesulfurization of Petroleum Resids. Catal. Today. 1998, 43, 261-272.

(3) Carrado, K. A.; Marshall, C. L.; Brenner, J. R.; Song, K. Materials Derived from Synthetic Organo-Clay Complexes as Novel Hydrodesulfurization Catalyst Supports. Microporous Mesoporous Mater. 1998, 20, 1726.

(4) Rhee, Y. W.; Guin, J. A.; Curtis, C. W. Effects of Pore Structure on Initial Catalystic Activity for Residuum Desulfurization and Coal Liquefaction. Energy Fuels. 1989, 3, 391-397.

(5) Li, C.; Chen, Y. W.; Yang, S. J.; Wu, J. C. Hydrodesulfurization Reactions of Atmospheric Gas Oil over CoMo/Alumina-Aluminum Borate Catalysts. Ind. Eng. Chem. Res. 1993, 32, 1573-1578.

(6) Aubert, C.; Durand, R.; Geneste, P.; Moreau, C. Hydroprocessing of Dibenzothiophene, Phenothiazine, Phenoxathiin, Thianthrene, and Thioxanthene on a Sulfided. J. Catal. 1986, 97, 169-176.

(7) Chen, Y. W.; Tsai, M. C. Hydrodesulfurization of Atomospheric Gas Oil Over NiMo/Alminum Borate Catalysts in a Trickle Bed Reactor. Ind. Eng. Chem. Res. 1997, 36, 2521-2525.

(8) Chen, Y. W.; Hsu, W. C. Hydrodemetalation of Residue oil over CoMo/Alumina-Aluminum Phosphate Catalysts in a Trickle Bed Reactor. Ind. Eng. Chem. Res. 1997, 36, 2526-2532.

(9) Duan, A.; Wan, G.; Zhao, Z.; Xu, C.; Zheng, Y.; Zhang, Y.; Dou, T.; Bao, X.; Chung, K. Characterization and activity of Mo supported catalysts for diesel deep hydrodesulphurization. Catal. Today 2007, 119, 13-18.

(10) Tsai, M. C.; Chen, Y. W. Restritive Diffusion under Hydrotreating Reactions of Heavy Residue Oils in a Trickle Bed Reactor. Ind. Eng. Chem. Res. 1993, 32, 1603-1609.

(11) Breysse, M.; Afanasiev, P.; Geantet, C.; Vrinat, M. Overview of support effects in hydrotreating catalysts. Catal. Today 2003, 86, 5-16.

(12) Turaga1, U. T.; Song, C. S. MCM-41-supported Co-Mo catalysts for deep hydrodesulfurization of light cycle oil. Catal. Today 2003, 86, 129-140.

(13) Li, X.; Wang, A.; Wang, Y.; Chen, Y.; Liu, Y.; Hu, Y. Hydrodesulfurization of dibenzothiophene over Ni-Mo Sulfides supported by protonexchanged siliceous MCM-41. Catal. Lett. 2002, 84 (1-2), 107-113.

(14) Ternan, M.; Rahimi, P. M.; Clugston, D. M.; Dettman, H. M. The $+525^{\circ}$ Residue Before and After Hydrocracking with Bimodal Catalysts of Varying Macropore. Energy Fuels 1994, 8, 518-530.

(15) Wang, W. P.; Guin, J. A. A Comparison of Unimodel and Bimodal Catalyst Deactivation Behavior in a Model Compound System with Rapid Coke Deposition. Fuel Process. Technol. 1991, 28, 149-166.

(16) Tsai, M. C.; Chen, Y. W. Restritive Diffusion under Hydrotreating Reactions of Heavy Residue Oils in a Trickle Bed Reactor. Ind. Eng. Chem. Res. 1993, 32, 1603-1609.

(17) Marafi, M.; Stanislaus, A. Effect of Initial Coking on Hydrotreating Catalyst Functionalities and Properties. Appl. Catal. A, Gen. 1997, 159 (12), 259-267.

(18) Kresge, C. T.; Leonowicz, M. E.; Roth, W. J.; Vartuli, J. C.; Beck, J. S. Ordered Mesoporous Molecular-Sieves Synthesized by a Liquid-Crystal Template Mechanism. Nature 1992, 359, 710-712.

(19) Sayari, A.; Kruk, M.; Jaroniec, M.; Moudrakovski, I. L. New Approaches to Pore-Size Engineering of Mesoporous Silicates. Adv. Mater. 1998, 10, 1376-1382.

(20) Sayari, A. Catalysis by Crystalline Mesoporous Molecular-Sieves. Chem. Mater. 1996, 8, 1840-1852.

(21) Corma, A.; Martinez, A.; Martinez-Soria, V.; Monton, J. B. Hydrocracking of Vacuum Gasoil on the Novel Mesoporous MCM-41 Aluminosilicate Catalyst. J. Catal. 1995, 153, 25-31.

(22) Carrado, K. A.; Marshall, C. L.; Brenner, J. R.; Song, K. Materials derived from synthetic organo-clay complexes as novel hydrodesulfurization catalyst supports. Microporous Mesoporous Mater. 1998, 20, 17-26.
(23) Schacht, P.; Noreña-Franco, L.; Ancheyta, J.; Ramírez, S.; Hernández-Pérez, I.; Garcí, L. A. Characterization of hydrothermally treated MCM-41 and Ti-MCM-41 molecular sieves. Catal. Today 2004, 98, 115121.

(24) Wang, A.; Ruan, L.; Teng, Y.; Li, X.; Lu, M.; Rena, J.; Wang, Y.; Hu, Y. Hydrodesulfurization of dibenzothiophene over siliceous MCM-41-supported nickel phosphide catalysts. J. Catal. 2005, 229, 314321.

(25) Sorensen, A. C.; Fuller, B. L.; Eklund, A. G.; Landry, C. C. MoDoped Mesoporous Silica for Thiophene Hydrodesulfurization: Comparison of Materials and Methods. Chem. Mater. 2004, 16, 2157-2164.

(26) Rivera-Muñoz, E.; Lardizabal, D.; Alonso, G.; Aguilar, A.; Siadati, M. H.; Chianelli, R. R. Silica gel- and MCM-41-supported $\mathrm{MoS}_{2}$ catalysts for HDS reactions. Catal. Lett. 2003, 85, 147-151.

(27) Cedeño, L.; Hernandez, D.; Klimova, T.; Ramirez, J. Synthesis of $\mathrm{Nb}$-containing mesoporous silica molecular sieves Analysis of its potential use in HDS catalysts. Appl. Catal. A, Gen. 2003, 241, 39-50.

(28) Liu, F.; Xu, S.; Cao, L.; Chi, Y.; Zhang, T.; Xue, D. A Comparison of $\mathrm{NiMo} / \mathrm{Al}_{2} \mathrm{O}_{3}$ Catalysts Prepared by Impregnation and Coprecipitation Methods for Hydrodesulfurization of Dibenzothiophene. J. Phys. Chem. C. 2007, 111, 7396-7402.

(29) Yuan, Z. Y.; Su, B. L. Insights into hierarchically mesomacroporous structured materials. J. Mater. Chem. 2006, 16, 663-677.

(30) Lin, H. P.; Mou, C. Y. Tubules-within-A-Tubule Hierarchical Order of Mesoporous Molecular-Sieves in MCM-41. Science 1996, 273, 765768.

(31) Lin, H. P.; Cheng, S. F.; Mou, C. Y. Mesoporous Molecular-Sieves MCM-41 with a Hollow Tubular Morphology. Chem. Mater. 1998, 10, 581589.

(32) Ling, T. R.; Wan, B. Z.; Lin, H. P.; Mou, C. Y. Optimum Synthesis Conditions for Tubular Shape MCM-41. The Proceedings of the 12th International Zeolite Conference, 1998, Materials Research Society, 1999; pp 931-938.

(33) Lin, H. P.; Cheng, S. F.; Mou, C. Y. Effect of Delayed Neutralization on the Synthesis of Mesoporous MCM-41 Molecular-Sieves. Microporous Mater. 1997, 10, 111-121.

(34) Lin, H. P.; Wong, S. T.; Liu, S. B.; Mou, C. Y.; Tang, C. Y. The Synthesis and Characterization of Mesoporous Molecular Sieves MCM-41 with Interconnected Channels. Stud. Surf. Sci. Catal. 2000, $129,15$.

(35) Lin, H. P.; Wong, S. T.; Mou, C. Y.; Tang, C. Y. Extensive Void Defects in Mesoporous Aluminosilicate MCM-41. J. Phys. Chem. B. 2000, 104, 8967.

(36) Chen, W. H.; Zhao, Q.; Lin, H. P.; Yang, Y. S.; Mou, C. Y.; Liu, S. B. Hydrocracking in Al-MCM-41: diffusion effect. Microporous Mesoporous Mater. 2003, 66, 209-218.

(37) Wong, S. T.; Lin, H. P.; Mou, C. Y. Tubular MCM-41 supported Transitional metal oxide Catalytst for Ethylbenzene Dehydrogenation Reaction. Appl. Catal. A, Gen. 2000, 198, 103-114.

(38) Lin, H. P.; Mou, C. Y. Structural and Morphological Control of Cationic Surfactant Templated Mesoporous Silica. Acc. Chem. Res. 2002, 35, 927-935.

(39) Ren, J.; Wang, A. J.; Li, X.; Chen, Y. Y.; Liu, H.; Hu, Y. K. Hydrodesulfurization of dibenzothiophene catalyzed by Ni-Mo sulfides supported on a mixture of MCM-41 and HY zeolites. Appl. Catal. A, Gen. 2000, 344, 175-182.

(40) Tan, Q. F.; Fan, Y.; Liu, H. Y.; Song, T. C.; Shi, G.; Shen, B. J.; Bao, X. J. Bimodal micro-mesoporous aluminosilicates for heavy oil cracking: Porosity tuning and catalytic propertie. AIChE J. 2008, 54, 18501859.

(41) Zheng, J. L.; Zhai, S. R.; Zhang, Y.; Wu, D.; Sun, Y. H.; Yang, Y. X.; Chen, L.; Deng, F. Hydrothermally stable MCM-41 analogue with extensive embedded voids. Catal. Today 2004, 93-95, 529-534.

(42) Hsu, Y. C.; Hsu, Y. T.; Hsu, H. Y.; Yang, C. M. Facile synthesis of mesoporous silica SBA-15 with additional intraparticle porosities. Chem. Mater. 2007, 19, 1120-1126.

Received for review September 25, 2008 Revised manuscript received November 25, 2008 Accepted December 4, 2008

IE8014389 